\title{
Abschied von einem Fähigkeitsausweis
}

\section{Thomas Hofer}

Dr. med., Facharzt für Dermatologie und Venerologie, Mitglied FMH

Jetzt ist es Tatsache geworden: ich habe die für die Rezertifizierung notwendigen Credits ganz einfach nicht mehr gesucht. Das Vorgehen, die Credits für das Modul Gefässe / Submodul periphere venöse Gefässe in kostbaren Kleinstdosen im ganzen Bannbereich der Schweiz auszulegen, hat die SGUM vor Jahrzehnten, Pokémon bereits vorausahnend, lust- und listvoll ausgetüftelt, und deren Ergattern lässt sich tatsächlich vergleichen mit dem Finden von Trüffeln. Natürlich kann man Trüffel kaufen und so bin ich bis jetzt gut über die Runden gekommen, indem ich alle paar Jahre die 2-tägigen Anfänger-/Grundkurse in Basel besucht habe. Irgendwie hielt mich dies jung trotz gleichzeitigem Altern. Der verantwortliche Kursleiter

\section{Wer von uns freut sich nicht immer wieder am Effekt des «Gugguseli - Dadaaaa!»?}

hat es nämlich über die Jahre hin geschickt verstanden, vergleichbar einem virtuosen Musiker, uns die technischen-physikalischen Raffinessen des Duplex so vorzutragen, dass ich jeweils mit der beruhigenden Gewissheit nach Hause ging, immer und wohlentsprechend in diesem Anfängerstatus verweilen zu dürfen. Ähnlich einem Kind habe ich so unbeschwert in den vergangenen mehr als 20 Jahren zigtausend Untersuchungen mit meinem schallenden Spielgerät gemacht, Thrombosen, Bakerzysten und was der Dinge alle es in den

\section{Der Abschied vom Fähigkeitsausweis fällt mir} leicht, und mein ganzer Dank gilt der SGUM.

Weichteilen der Beine da gibt gejagt und aufgescheucht und über 5000 Patienten an ihren Varizen operiert. Wie gross war und ist bis heute die ungebrochene Freude des Anfängers, dass die von mir präoperativ eingezeichneten transfaszialen Refluxquellen peroperativ auch wirklich exakt dort zu finden waren und sind. Wer von uns (60 und älter, Enkel vorausgesetzt) freut sich nicht immer wieder am Effekt des «Gugguseli Dadaaaa!»?

Doch mit der kommenden, in Raten zu vollziehenden Pensionierung wird der hinausgezögerte Bruch mit der Kindheit Tatsache. So bin ich dankbar dafür, dass sich im Laufe der Jahre die Entwicklung der Ultraschalluntersuchung der Krampfadern in horrendem Tempo revolutioniert hat. Ich denke dabei an den Bildschirm, der immer breiter wird oder an die Auflösung des Bildes, die zwischenzeitlich praktisch nur noch mit der Sonnenbrille zu ertragen ist, um nur zwei Beispiele zu nennen. Zudem legt die moderne Krampfaderngeneration kaum mehr Wert auf ein in schwungvollen Windungen daherkommendes Erscheinen. Dem blossen Auge noch kaum erkennbar wird sie von Jägern und Wilderern bereits aufgestöbert und flugs verdampft oder zerschüttelt. Der Abschied vom Fähigkeitsausweis fällt mir leicht, und mein ganzer Dank gilt der SGUM, die es mir ermöglicht hat, mich zukünftig auf dem in aller Heimlichkeit geäufneten Duplexkissen auszuruhen. Meine Patienten und ihre Versicherer wiederum werden es mir danken, wenn ich ihnen zukünftig Bild und Farbe schenken werde. 